\title{
Assessing student teams developing mathematical models applied to business and industrial mathematics
}

Edmund Chadwick

School of Computing, Science and Engineering

University of Salford

E.A.Chadwick@salford.ac.uk

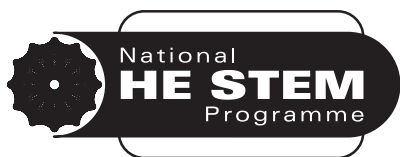

Work supported by the HE Curriculum Innovation Fund, part of the National HE STEM Programme Mathematical Sciences Strand.

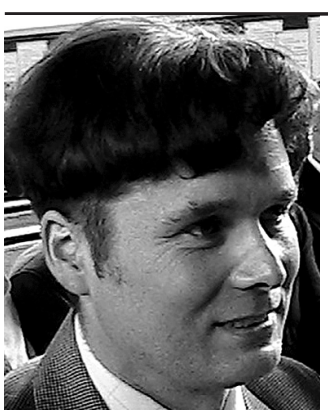

Kevin Sandiford

School of Computing, Science \& Engineering University of Salford

k.sandiford@salford.ac.uk

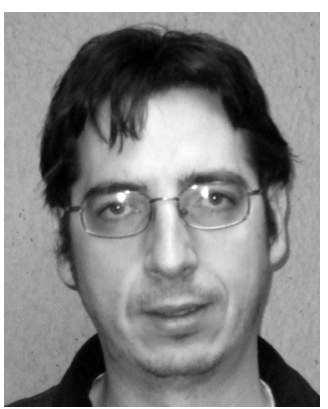

David Percy

School of Computing, Science \& Engineering University of Salford d.f.percy@salford.ac.uk

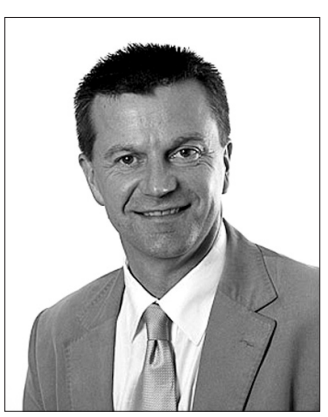

Using case studies and group work, this project attempted to provide students with experience of business and industrial working practices and also to address the issue of how to solve practical mathematical problems. Students were organised into teams and tasked with solving a problem presented in the form of a real world industrial case study. Each group was assessed on their problem solving abilities, mathematical modelling skills and also on their team work and contribution to the group. Industrial partners were also invited to judge the final solutions presented by the group and feedback was offered, based on the 'real world' situation presented by the case studies.

\section{Background and Rationale:}

The methodology used to tackle the issue of problem solving was not a traditional academic route by examination or essay, but instead a pro-active approach through a team-based problem-solving format familiar to the world of business and industry. The idea for this approach was to prepare the students for the world of work and to highlight the way in which they will be expected to use their mathematical knowledge in their future careers. A vital part of this was exposure, understanding and experience of the development of mathematical models from concept to testing.

Throughout the module, seminars from guest speakers on a spectrum of mathematical applications used in industry would expand the 'real world/industrial' context to give students insight into the world of work and the way mathematics may be used in their jobs. The module task would assess the students' ability to do this. Industrial partners identified team working and problem solving as areas of vital importance so this project attempted to incorporate both into a series of tasks.

Students would be exposed to the various roles played within a team and so have the opportunity to assess their preferences, performance and capacity for changing role particularly in the context of developing mathematical models. This would provide valuable information to the student in understanding their strengths and weaknesses within group dynamics while also providing opportunity for reflection and change.

By the end of the module, the students would have had real experience of the type of roles played within teams, and be able to reflect upon how this dynamic directed the outcome of the task solution as well as how they responded to it. They would have been tested and assessed for a variety of business-like attributes not assessed by a standard academic module. This would help us produce more business-aware and business-ready graduates for the workplace. 


\section{Implementation:}

The industrial speakers represented a range of different sections and included: DSTL, CMS intelligent banking, Manchester Medical Academic Health Sciences (NHS), IBM, an expert court case witness, IMA, and the Sellafield OR group. The industrial list was compiled from existing staff contacts and graduate alumni from the university. As well as describing what they do, which was almost exclusively mathematical modelling, the guest speakers also described the group structure of their companies, essentially project leaders managing small teams.

These talks were intended to provide an insight into working practices and demonstrate how the course structure and content reflects the industrial world. Topics covered by the talks included the career path, company profile and use of mathematics by the company. The work practices covered problem solving, communication and team-working thus providing the context, understanding and direct connection from the module to the world of work.

Two open-ended case studies were presented consecutively to student teams. The case study titles were:

1. What are the hours of daylight and darkness?

2. What is a variable APR mortgage?

The titles chosen were deliberately open-ended, and the mathematics required trigonometry and series respectively, typically to A-Level standard, so as to free the groups to follow their own direction for solution.

Students were arranged into teams of four members. Each member was given a specific role, and the team members and roles changed upon completion of each case study. The groups were left to organise themselves, arrange meetings and liaise with an academic adviser.

The four roles in each group were chair, secretary, task coordinator and technical coordinator. The groups worked on developing a mathematical model to answer the case study questions from concept, design and solution, through to testing. Groups were required to produce a minutes book, project plan, specification and final report which detailed their mathematical model. They were also required to give a group PowerPoint presentation for an audience of industrialists and academic staff, to which each team member contributed. Following these presentations the audience offered immediate feedback.

The academic adviser played a supportive role and was required only to respond to questions from the group. The academic adviser observed and noted the interaction between members of the groups, and how they adapted to being given roles and the change in roles between case studies. Both adviser and students were required to share reflective comments on this experience as part of a wider personal development process for the students.
As well as the academic advisers, the module coordinator had responsible for contacting, inviting and arranging the visits of guest speakers from business and industry, facilitating the meetings scheduled between the academic adviser and the student groups, making the students aware of the format of the deliverables with deadlines via the handbooks and the case studies, as well as organising the schedule for the student group presentations attended by the group of industrialists.

\section{Evaluation}

Evaluation took the form of feedback from the students and industrialists. Feedback from the students was required in the final report, in the presentation, and also in a separate reflection sheet. Feedback from the industrialists was given verbally.

From the students' final reports, there was significant positive feedback. They were asked to give an evaluation of the success of their project, identify what worked and went well and what did not work. The evaluation of the project covered the group dynamics as well as the deliverable outputs. The general response to this section was that they saw this project as an opportunity to problem-solve and provide their own solution, which was a "refreshing change" from the format in other modules.

However some negative feedback was present around group dynamics, in particular about group members that didn't contribute significantly and didn't come to prearranged meetings. One suggestion to resolve this might be to attempt to evenly distribute the students so each group had a balanced cross-section of ability and motivation, as the main problems came when two or more poorly motivated students resided in the same group.

In terms of the presentations, the students were very critical of themselves focusing in on what went wrong. They did not give balanced critiques which also highlighted the positives.

In the reflection sheets, students were asked to highlight key decisions that most influenced the direction of the assignment, which roles they preferred and how their involvement changed with the change in role. Although no common themes came out of these sheets as they reflected the personal involvement of each student; in writing down and having to reflect in this way, it is clear from the majority that the students were starting to reflect on their personal preferences within a group. It was also clear that their interaction changed with changing role, and each role was beneficial in developing them in different ways. It could be interesting in the future to see if more could be made of this, in terms of feeding into the student understanding their personal preferences, feeding into a personal development plan.

Feedback from the industrialists was given verbally and expressed the view that this type of project was immensely valuable in exposing the students to the type of work and 
working environment that would be expected of them in their future jobs. They said the case studies posed were challenging and that they were surprised by the high academic level achieved by the groups in the reports and presentations, and the variation in the directions taken by each group.

This work was presented at the Embedding Graduate Skills workshop in November 2010 at Sheffield Hallam University and at the CETL-MSOR Conference 2011. It was written up for the Developing Graduate Skills booklet [1].

\section{Discussion}

The principal goal, of exposing students to a problemsolving way of working akin to the work environment developing mathematical models, was successful. The realistic structure of the project task and the industry involvement through the seminar series and assessment made the task and the mathematics relevant to the students enabling them to see how their course is used in industry. This is one key reason why the approach was successful and appeared to make the module less 'academic' in the eyes of the students.

Another important success was in getting the students to think about how they worked in the reflection sheets and to start reflecting on their actions. This was successful in terms of the student response, in that they found it beneficial to themselves, although it was not directly assessed. As mentioned above, this type of activity could be used to feed into a personal development plan to identify the strengths and weaknesses of individuals in order for them to focus on such areas for growth.

A key lesson that was learned was that industrial involvement was paramount for success. Although not essential to the running of the module, the students responded to and respected the input and advice given by the company representatives over that given by the academics or careers staff. The company involvement made the content of the module real and relevant.

Also, the difficulty in obtaining a meaningful evaluation was highlighted. Feedback in the presentations and reports from the students focussed on the negatives of group members and of their own input. The students seemed unable to make a rounded assessment and present the positive aspects of their work.

\section{Further development and sustainability}

Future development will consider more carefully how to evaluate and adapt the wording used on feedback and reflection sheets to try to draw out more of the personal development that is taking place. It will be emphasised that a rounded critique rather than a negative criticism is required. More emphasis in the final report could be placed on the students' assessment of their personal and group development, perhaps with an additional section required on this.

An online peer assessment system such as WebPA [2] could be introduced as a possible alternative to assessing the group work element.

The students' overwhelming recommendation is for the module to be run again, and the university is committed to sustaining this as an essential embedded module within the degree programme for the foreseeable future.

\section{References}

1. Chadwick, E. (2011). Student Teams Developing Mathematical Models Applied to Business and Industrial Mathematics. In: J. Waldock (ed) Developing Graduate Skills in HE Mathematics Programmes: case studies of successful practice, pp. 36-38.

2. WebPA http://webpaproject.lboro.ac.uk/ [last accessed 10/10/2011].

\section{A Statistical Awareness Curriculum for STEM Employees}

\section{Project leader: Neville Davies, RSS Centre for Statistical Education, Plymouth University}

For STEM employers and employees we will produce:
a) a web-based survey tool to audit the statistical skills of their workforce;
b) a curriculum, freely available via the RSSCSE web site, that can be taught to STEM employees using distance learning.

We will identify a range of topics under three headings related to what STEM employees should:

i. know about; ii. be able to identify and critically evaluate;

iii. be able to fully understand or do.

Educational providers will be able to use the curriculum, specification, exemplars and resource links to create courses to deliver the material.

This project is supported by the Mathematical Sciences HE Curriculum Innovation Project, part of the National HE STEM Programme. 